\title{
China's socioeconomic risk from extreme events in a changing climate: a hierarchical Bayesian model
}

\author{
Xiao-Chen Yuan ${ }^{\mathrm{a}, \mathrm{b}}$, Xun Sun ${ }^{\mathrm{c}}$, Upmanu Lall ${ }^{\mathrm{c}, \mathrm{d}}$, Zhi-Fu Mi ${ }^{\mathrm{a}, \mathrm{b}}$, Jun He ${ }^{\mathrm{e}}$, Yi-Ming Wei ${ }^{\mathrm{a}, \mathrm{b}, *}$ \\ a. Center for Energy and Environmental Policy Research, Beijing Institute of Technology, Beijing 100081, China \\ b. School of Management and Economics, Beijing Institute of Technology, Beijing 100081, China \\ c. Columbia Water Center, Earth Institute, Columbia University, New York, NY 10027, USA \\ d. Department of Earth and Environmental Engineering, Columbia University, New York, NY 10027, USA \\ e. Key Laboratory of Water Cycle \& Related Land Surface Processes, Institute of Geographic Sciences and Natural \\ Resources Research, Chinese Academy of Sciences, Beijing 100101, China
} ${ }^{*}$ Corresponding author: Center for Energy and Environmental Policy Research, Beijing Institute of Technology (BIT), 5
South Zhongguancun Street, Beijing 100081, China.

Tel./ Fax: +86-10-68918651

E-mail: ymwei@deas.harvard.edu, wei@bit.edu.cn (Y.-M. Wei) 
China has a large economic and demographic exposure to extreme events that is increasing rapidly due to its fast development, and climate change may further aggravate the situation. This paper investigates China's socioeconomic risk from extreme events under climate change over the next few decades with a focus on subnational heterogeneity. The empirical relationships between socioeconomic damages and their determinants are identified using a hierarchical Bayesian approach, and are used to estimate future damages as well as associated uncertainty bounds given specified climate and development scenarios. Considering projected changes in exposure we find that the southwest and central regions and Hainan Island of China are likely to have a larger percentage of population at risk, while most of the southwest and central regions could generally have higher economic losses. Finally, the analysis suggests that increasing income can significantly decrease the number of people affected by extremes.

Keywords: socioeconomic risk, hierarchical Bayesian, natural disasters, climate change

\section{INTRODUCTION}

Climate change has significant impacts on society, and is a global challenge (IPCC 2013, 2014). From a policy perspective an assessment of the potential damage with changing concentration of greenhouse gases (GHGs) is of interest. Region-specific damage from extreme events plays a significant role in calculating the costs of GHG emissions (van den Bergh and Botzen 2014), especially for the more vulnerable, developing countries (Fankhauser and McDermott 2014). More importantly, the uncertainty of future damages is a key issue for adaptation planning and risk mitigation, and is receiving more attention (Rogelj et al. 2013; Wei et al. 2015). Here, we present an empirical analysis of regional socioeconomic impacts due to extreme events in China, using a statistical model that is effective for quantifying the uncertainty in the relationships.

China has experienced heavy losses from weather-related disasters. For example, the average direct losses caused by floods during 1990-2012 were 130.3 billion CNY (current price) annually, and because of droughts there were on average 27.3 million people per year who did not have access to drinking water during 1991-2012 (State Flood Control and Drought Relief Headquarters of China 2013). With rising temperatures, China may also face higher 
risk of adverse consequences. These impacts differ across regions owing to natural and social factors. Consequently, an assessment of China's future damages from extreme events is attracting the attention of decision makers.

There are two common ways to model the damages resulting from disasters, process-based models (Arnell and Lloyd-Hughes 2014; Hallegatte et al. 2013; Wang et al. 2015) and statistical models (Hsiang 2010; Lloyd et al. 2016; Patt et al. 2010). In practice process-based models usually rely on a large number of high-resolution climatic, geographic, and socioeconomic data sets to describe the complex natural process. However, this approach may be challenged in some regions of limited data sets and is relatively difficult to consider model uncertainty. By comparison, statistical approaches are less data-intensive and easily applied to the analysis with diversified geographic coverage. In addition, it also provides an opportunity to estimate model uncertainty in a formal way. An investigation of the statistically significant driving forces for the impacts could help explain vulnerability to extremes, and advance policy making (Barr et al. 2010; IPCC 2012; Thomas et al. 2014; Tol 2002).

Socioeconomic damages from weather-related disasters, which generally refer to the adverse impacts on people and economy, depend on various aspects (Bahinipati and Venkatachalam 2016; IPCC 2012; Lazzaroni and van Bergeijk 2014; Liu et al. 2015; Morss et al. 2011). The physical characteristic (e.g. frequency, magnitude and intensity) of extreme hazards directly relates to damages (Nordhaus 2010; Pielke 2007; Schumacher and Strobl 2011; Seo 2014). Socioeconomic development can also have significant effects. Growing wealth and population increases socioeconomic exposure, therefore increasing potential losses (Cavallo et al. 2010; Kebede and Nicholls 2012; Mendelsohn et al. 2012; Preston 2013). At the same time, economic development could enhance adaptive capacity and therefore help mitigate damages (Fankhauser and McDermott 2014; Kellenberg and Mobarak 2008; Smit and Wandel 2006; Zhou et al. 2014). There is evidence that high-income areas are generally more likely to have strong adaptive capacity to deal with extreme events (Kahn 2005; Noy 2009; Raschky 2008; Toya and Skidmore 2007).

Establishing a relationship between socioeconomic damages and associated influencing factors is essential for estimating future potential cost. However, uncertainties in such structural relations have not been formally considered for damage estimation in previous studies using traditional regression techniques. A hierarchical 
Bayesian approach can help quantify model and parameter uncertainties, and provides an opportunity for uncertainty reduction through partial pooling of the common information from different regions while considering heterogeneity (Gelman and Hill 2007). Such methods have been employed to flexibly construct statistical relationships in some fields (Chen et al. 2014; Devineni et al. 2013; Sun et al. 2015). For climate change impact analysis, a hierarchical Bayesian model could help provide reasonable ranges of potential damages.

At present, there are few studies on China's socioeconomic consequences of extreme events at the sub-national level, especially under future climate conditions. There is a need for a representation of model and parameter uncertainties for long-term prediction. This paper contributes to the empirical analysis of the potential impacts of extremes in China by formally modelling uncertainty, and the projections of provincial socioeconomic risk under climate change. To do so, a hierarchical Bayesian model is developed at the provincial level of China to detect the relationships between socioeconomic damages and their determinants. When presenting regional and national socioeconomic risk, we also take into account the uncertainty of future extreme events.

The rest of this paper is organized as follows. In Section 2, we describe data sets, scenario assumptions, and hierarchical Bayesian model. Section 3 presents the results of empirical models and predictions of socioeconomic damages. Finally, Section 4 concludes the paper and makes some recommendations for China's adaptation and mitigation plans.

\section{METHODOLOGY}

\subsection{Study area and data description}

Thirty provinces (including municipalities and autonomous regions) of China were taken as a study area (see Figure S1 for locations and Table S1 for name abbreviations in the supplementary material). Shanghai has zero damage observations (economic losses or affected people) in several years partly due to low geographic exposure, and hence it is not included in our analysis.

The historical meteorological data for the period 1970-2012 are taken from China Meteorological Data Sharing Service System. Daily time series for the selected weather stations (shown in Figure S1) include precipitation, mean temperature, maximum temperature, and minimum temperature. The 1970-2050 simulated monthly 
precipitation and mean temperature under Representative Concentration Pathways (RCPs) come from the downscaled outputs (grid with $0.5^{\circ} \times 0.5^{\circ}$ resolution) of five climate models (HadGEM2-ES, IPSL-CM5A-LR, MIROC-ESM-CHEM, GFDL-ESM2M, and NorESM1-M) provided by the Inter-Sectoral Impact Model Intercomparison Project (ISI-MIP). We transformed them into the grids at $0.1^{\circ}$ resolution so as to calculate different climate conditions at the county level. Then the future climate data of counties are used as projections for the corresponding weather stations based on their locations. The meteorological data are taken to identify and predict each station's extreme events (Table S2). For each type of extreme the mean number of events of the stations within a province is calculated for provincial analysis. We separately detect the impacts of climate models, and their average results are displayed in this study.

China Civil Affairs' Statistical Yearbook provides annual total direct economic losses and number of people affected due to weather-related disasters (including flood, waterlogging, typhoon, drought, low-temperature, snow, etc.) at the provincial level, and those during 2000-2012 (excluding 2004) are picked out. The economic losses (constant $2010 \mathrm{CNY}$ ) are obtained by the implicit price deflator for gross domestic product (GDP). The provincial economic and demographic data during 2000-2012 are collected from China Statistical Yearbooks as well as China Socioeconomic Development Statistical Database.

The shared socioeconomic pathways (SSPs) describe the storylines of possible future (O'Neill et al. 2014), and the intermediate case SSP2 is used for the development scenario. The projections of national population and GDP growth rate from OECD in the SSP Database (https://secure.iiasa.ac.at/web-apps/ene/SspDb) are only made for the whole country, and accordingly they are disaggregated to provinces. We focus on three RCPs for the climate scenarios. van Vuuren and Carter (2014) suggest that RCP6.0 is compatible with SSP2, and we further evaluate RCP2.6 and RCP4.5 as climate policy mitigation scenarios.

\subsection{Determinants of socioeconomic damages}

In this paper we quantify socioeconomic damages in terms economic losses and the number of people affected (i.e. the population with adverse consequences from disasters). The economic development and population in China vary from region to region, so the two indicators can help better reveal the regional patterns of socioeconomic damages. According to previous studies (Fankhauser and McDermott 2014; Kahn 2005; Kellenberg and Mobarak 2008; Patt et al. 2010), the determinants of socioeconomic damages are selected from climatic and socioeconomic 
aspects. Specifically, the variables including the number of flood-related events $(N U M F)$, the number of drought events $(N U M D)$, the number of heat events $(N U M H)$, the number of cold-related events $(N U M C)$, population $(P O P)$, gross domestic product $(G D P)$, and GDP per capita $(G D P P C)$ are used in the analysis. The number of extreme events indicates the frequency of extremes occurring within a region, and population and GDP reflect demographic and economic exposure to extremes respectively. GDP per capita is taken to measure adaptive capacity (Fankhauser and McDermott 2014). In the following, we explain in details how these variables are derived under future scenarios.

We consider four types of extremes (as defined in Table S2) relative to the recorded damages from weatherrelated disasters in China. The historical extreme events at each station are identified from the observed climate data, and the mean number of events across the stations within a province is used for provincial analysis. For each type of extreme the relationship between the annual number of events and the associated climate variable (Table S2) is constructed at each station, and then the future number of extremes is derived from the projected climate variable of climate models under RCPs. The uncertainty in the predicted number of extreme events is also considered by modelling its distribution. Since the simulated and observed climate variables are not identical in distribution, the data for them during 1970-2000 are used to correct the distribution of simulated climate variables. The bias correction of temperature-related variables is based on a Normal distribution (Hawkins et al. 2013). Similarly, annual total precipitation is corrected by a Log-Normal distribution due to skewness.

The provincial economic development is derived from the projected growth rate of national GDP provided by the SSP2 scenario at a 10-year interval. First, we linearly interpolate the values over the time intervals to get annual GDP growth rate of China by 2050. Second, the structure of provinces' growth rate is assumed to be the same as that in 2012. Accordingly, future GDP in each province can be calculated. In our analysis, GDP is in constant $2010 \mathrm{CNY}$.

For the demographic scenario, population at the provincial level is assumed according to the results from SSP2 which gives the projections of China's total population up to 2050 at a 10 -year interval. First, we linearly interpolate the values over the time intervals to get annual total population of China by 2050. Second, the allocation of the country's total population to each province is calculated using population coefficients. Here the 
ratio of a province's population to the country's total is defined as the province's population coefficient, and the assumed coefficients are adjusted in accordance with their variations during 2006-2012.

The empirical relationships between damages and their determinants are explored using a hierarchical Bayesian model, and these are then used to make damage projections over 2015-2050. The socioeconomic damages separately calculated with the outcomes of different climate models are averaged to represent future estimate. The uncertainties of our model and associated climate inputs are taken into account to illustrate national and regional risk from extreme events. Also, we compare the damages in the past and future to reveal the effect of climate change with the unchanged socioeconomic situation.

\subsection{Hierarchical Bayesian model for socioeconomic damage}

A multilevel model is considered. At the first level, a log-log relationship between damages and socioeconomic as well as climate covariates was selected after a preliminary diagnostic evaluation. For the $s$ th $(s=1,2, \ldots, S)$ province in year $t$, the number of people affected $y_{s t}$ and economic losses $z_{s t}$ (both log transformed) are modelled with a bivariate normal distribution which considers the dependence across the two variables.

$$
\left(\begin{array}{c}
y_{s t} \\
z_{s t}
\end{array}\right) \sim \operatorname{MVN}\left(\begin{array}{c}
\beta_{0, s}+\beta_{1, s} x_{1, s t}+\beta_{2, s} x_{2, s t}+\ldots+\beta_{J, s} x_{J, s t} \\
b_{0, s}+b_{1, s} v_{1, s t}+b_{2, s} v_{2, s t}+\ldots+b_{K, s} v_{K, s t}
\end{array}\right)
$$

where MVN denotes a multivariate Normal distribution; $\mathbf{x}_{s t}=\left(x_{1, s t}, x_{2, s t}, \ldots, x_{J, s t}\right)$ is a set of $J$ covariates associated with the number of people affected of province $s$ in year $t$; similarly $\mathbf{v}_{s t}=\left(v_{1, s t}, v_{2, s t}, \ldots, v_{K, s t}\right)$ is a set of $K$ covariates associated with economic losses. The regression coefficients $\boldsymbol{\beta}_{s}=\left(\beta_{0, s}, \beta_{1, s}, \beta_{2, s}, \ldots, \beta_{J, s}\right)$ and $\mathbf{b}_{s}=\left(b_{0, s}, b_{1, s}, b_{2, s}, \ldots, b_{K, s}\right)$ and the covariance matrix $\boldsymbol{\Sigma}_{s}$ all need to be estimated. Eq. (1) is the model applied directly to the variables of interest.

At the second level of the model, we assess the spread of covariate effects across provinces. A multivariate Normal distribution is considered for the regression coefficients $\boldsymbol{\beta}_{s}$ and $\mathbf{b}_{s}$, respectively (Chen et al. 2014; Devineni et al. 2013; Kwon et al. 2011). The corresponding equations are expressed as

$$
\boldsymbol{\beta}_{s} \sim \operatorname{MVN}\left(\boldsymbol{\mu}_{\beta}, \Sigma_{\beta}\right)
$$


where $\boldsymbol{\mu}_{\beta}$ (a vector of length $J+1$ ) and $\boldsymbol{\mu}_{b}$ (a vector of length $K+1$ ) are the common mean regression coefficients for all the provinces; correspondingly, $\boldsymbol{\Sigma}_{\beta}$ and $\boldsymbol{\Sigma}_{b}$ are the covariance matrices. If the estimated variances of $\boldsymbol{\beta}_{s}$ and $\mathbf{b}_{s}$ (diagonal of $\boldsymbol{\Sigma}_{\beta}$ and $\boldsymbol{\Sigma}_{b}$ ) are large, then effectively it indicates a no-pooling model where each province is regressed independently; by contrast, small variances imply a full pooling model with homogeneous responses to the influencing factors (Gelman and Hill 2007). We use non-formative priors for the parameters $\boldsymbol{\Sigma}_{s}, \boldsymbol{\mu}_{\beta}, \boldsymbol{\Sigma}_{\beta}, \boldsymbol{\mu}_{b}$ and $\boldsymbol{\Sigma}_{b}$, and employ Markov Chain Monte Carlo (MCMC) sampling to estimate posterior distributions. The convergence of the MCMC chain is evaluated by the potential scale reduction factor (Gelman and Rubin 1992), and all the calculations are conducted using R and RStan (Stan Development Team 2015).

Two models (Table 1) are developed. Specifically, in Model 1 the variables including the number of flood-related events, the number of drought events, the number of heat events, and the number of cold-related events are used for both the damages. Population is considered for the number of people affected, while gross domestic product is involved in the estimation of economic losses. The variables in this model are related to exposure only, and thus Model 1 is taken as the baseline model that reveals the effect of exposure on damages. GDP per capita that reflects adaptive capacity is introduced into Model 2. As a result, Model 2 reveals the effects of exposure and adaptation on damages. These two models present different potential ranges of damages which are both meaningful for policy making. That is, the possible more severe consequences derived from the models could help risk management, and the differences in the estimates between two models could provide insights for damage mitigation. The log transformation is applied to all the variables in the regressions, and dependent variables refer to number of people affected (thousand persons) and economic losses (billions).

Table 1 Variables included in the models for socioeconomic damages

\begin{tabular}{lllll}
\hline Independent variable & \multicolumn{3}{l}{ Model 1 } & \multicolumn{2}{l}{ Model 2 } \\
\cline { 2 - 5 } & $\begin{array}{l}\text { Number of } \\
\text { people affected }\end{array}$ & $\begin{array}{l}\text { Economic } \\
\text { losses }\end{array}$ & $\begin{array}{l}\text { Number of } \\
\text { people affected }\end{array}$ & $\begin{array}{l}\text { Economic } \\
\text { losses }\end{array}$ \\
\hline Number of flood-related events $(N U M F)$ & $\times$ & $\times$ & $\times$ & $\times$ \\
Number of drought events $(N U M D)$ & $\times$ & $\times$ & $\times$ & $\times$ \\
Number of heat events $(N U M H)$ & $\times$ & $\times$ & $\times$ & $\times$ \\
\hline
\end{tabular}




\begin{tabular}{lllll}
\hline Number of cold-related events $(N U M C)$ & $\times$ & $\times$ & $\times$ & $\times$ \\
Population $(P O P)$ & $\times$ & & $\times$ & $\times$ \\
Gross domestic product $(G D P)$ & & $\times$ & $\times$ \\
Gross domestic product per capita $(G D P P C)$ & & & $\times$ \\
\hline
\end{tabular}

\section{RESULTS AND DISCUSSION}

\subsection{Empirical regressions for socioeconomic damages}

Two forms of socioeconomic damages are investigated which are the number of people affected and economic losses. We start with the results on affected people and then economic losses for the two models.

The estimated posterior distributions of regression coefficients for Model 1 are presented in Figure S2 and S3. The parameter whose $90 \%$ interval of the posterior distribution does not overlap with 0 is regarded to have a significant effect. Based on the estimated common mean regression coefficients for all provinces, flood-related events and heat events increase by $1 \%$ would lead to the $0.34 \%$ and $0.25 \%$ (median values) increments in the affected people respectively. These are generally higher than those for drought events and cold-related events. We also find that the growth of population creates larger demographic exposure to extremes with the average elasticity of 0.83 (median value), which suggests that affected people would increase almost proportionally to the increment of population. For economic losses, the scale of economy instead of population is taken into account. It can be found that a $1 \%$ increase in flood-related events and heat events would result in the $0.41 \%$ and $0.20 \%$ (median values) average increments in economic losses, respectively. However, drought events and cold-related events seem to have insignificant impacts. In addition, GDP would raise losses because of growing economic exposure.

The estimated regression coefficients for Model 2 are shown in Figure S4 and S5. The coefficient for GDP per capita shows that adaptive capacity would significantly decrease both the number of people affected and economic losses. These findings are consistent with those in the literature. Here the effects of exposure and adaptation are included in the model. 
We notice that most predictors have different effects across the provinces, which implies that the partial pooling regression employed by this study is reasonable. Though some variables have insignificant impacts, we retain them for prediction since they can still provide some information for the posterior distribution of damage.

By spatially pooling the regression coefficients across provinces, we jointly model two kinds of damages with a multivariate distribution considering their dependence. Also, the results without dependence are made for further comparison. The interquartile ranges for the regression coefficients in Model 1 by joint and separate modeling of affected people and economic losses are presented in Figure S6. It can be seen that the joint model generally reduces the uncertainty of parameter estimation. Consequently, our model is expected to provide more precise socioeconomic damages which are important for making adaptation and mitigation plans.

\subsection{Regional patterns of socioeconomic risk}

The socioeconomic damages over 2015-2050 are predicted for future climate and development scenarios, and Figure 1 illustrates the average damage projections based on Model 1. Here, only the damages under RCP2.6 are shown, because the differences in the estimates between RCPs are small. It can be seen that the southwest provinces (Guizhou, Chongqing, Yunnan, Guangxi, and Sichuan), the central provinces (Jiangxi, Hubei, and Hunan), and Hainan Island are likely to have a larger percentage of population at risk. The estimates are consistent with the historical facts that south China suffered from more people affected in total population. These provinces generally have a less developed economy which gives lower adaptive capacity to disasters. The emergency response capacity for catastrophe in these areas is weaker, contributing to heavier damages. Higher losses are also indicated for most of the southwest and central areas, especially for Sichuan and Hunan. Some high-income provinces such as Guangdong, Zhejiang, Shandong, and Inner Mongolia may experience high losses, even the increase in the number of people affected may not be as high. By comparison, lower economic losses are found in the less developed provinces such as Tibet, Ningxia, and Qinghai. 


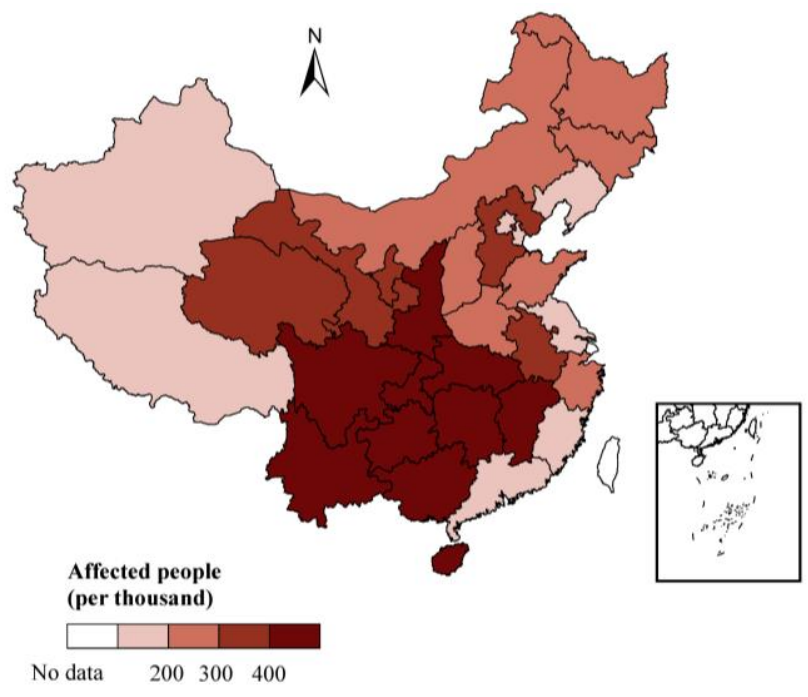

(a)

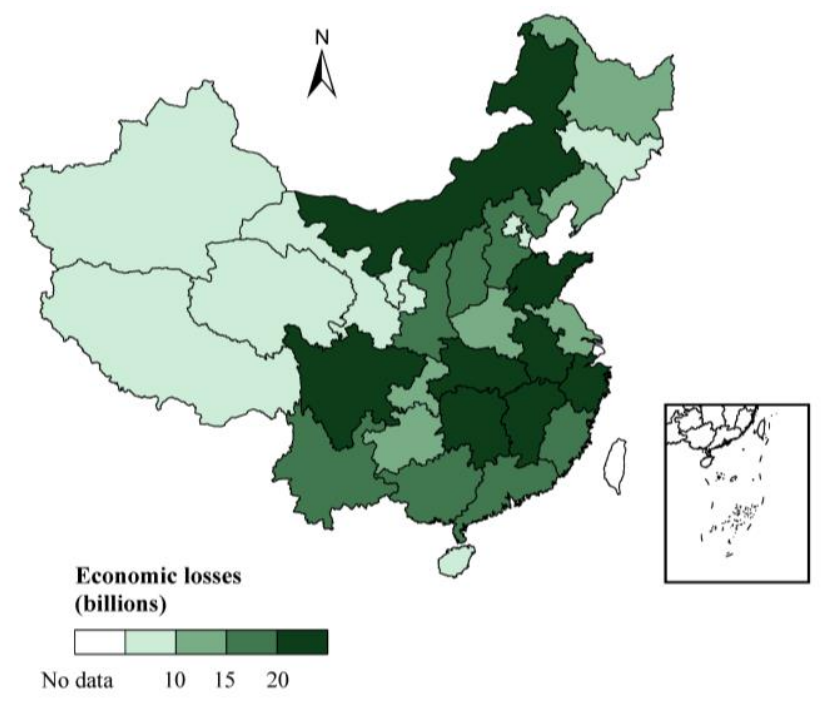

(b)

218 Figure 1 Average socioeconomic damages (median value) during 2015-2050 under RCP2.6. Note that affected people are represented by the share in total population.

Figure 2 displays the changes in the average number of affected people predicted by both models under RCP2.6, as well as the average from observations during 2000-2012. The estimated medians of the average people affected with adaptation are all smaller, and in some provinces the whole range of predictions lies below the historical average. Correspondingly, the average economic losses are shown as Figure 3. It also indicates that adaptation reduces impact. Due to the increased GDP, the predicted economic losses with adaptation effect are not far away from the historical averages in most provinces; by comparison, those without adaptation are higher.

On the whole, two models give a wider range of potential socioeconomic damages for risk management. Also, they imply that economic development plays an important role in damage mitigation, and this is of importance for vulnerable areas. 

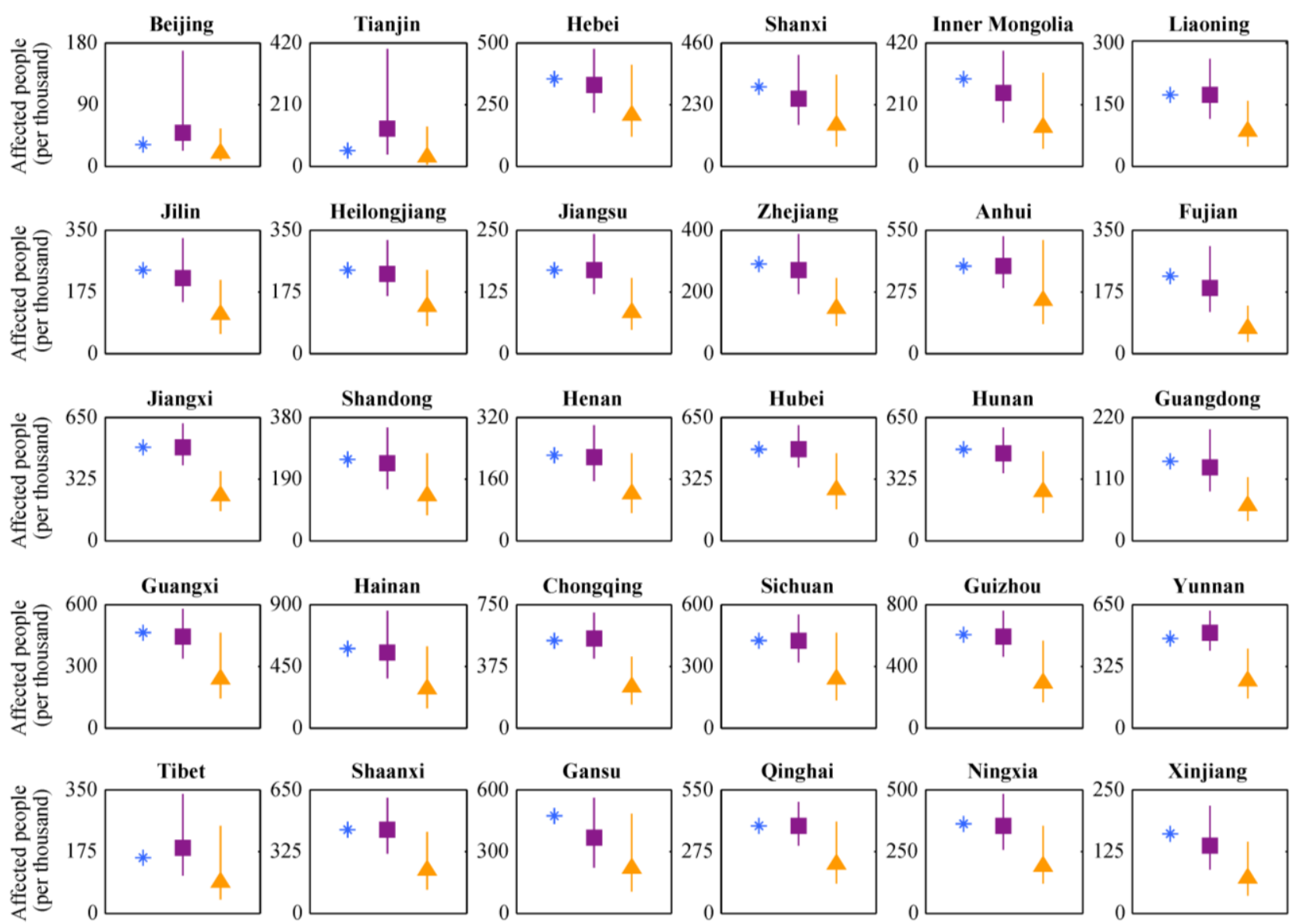

230 Figure 2 Average affected people recorded in 2000-2012 and predicted in 2015-2050 under RCP2.6 (2.5-97.5\%

231 uncertainty bound with median value). Note that affected people are represented by the share in total population. 

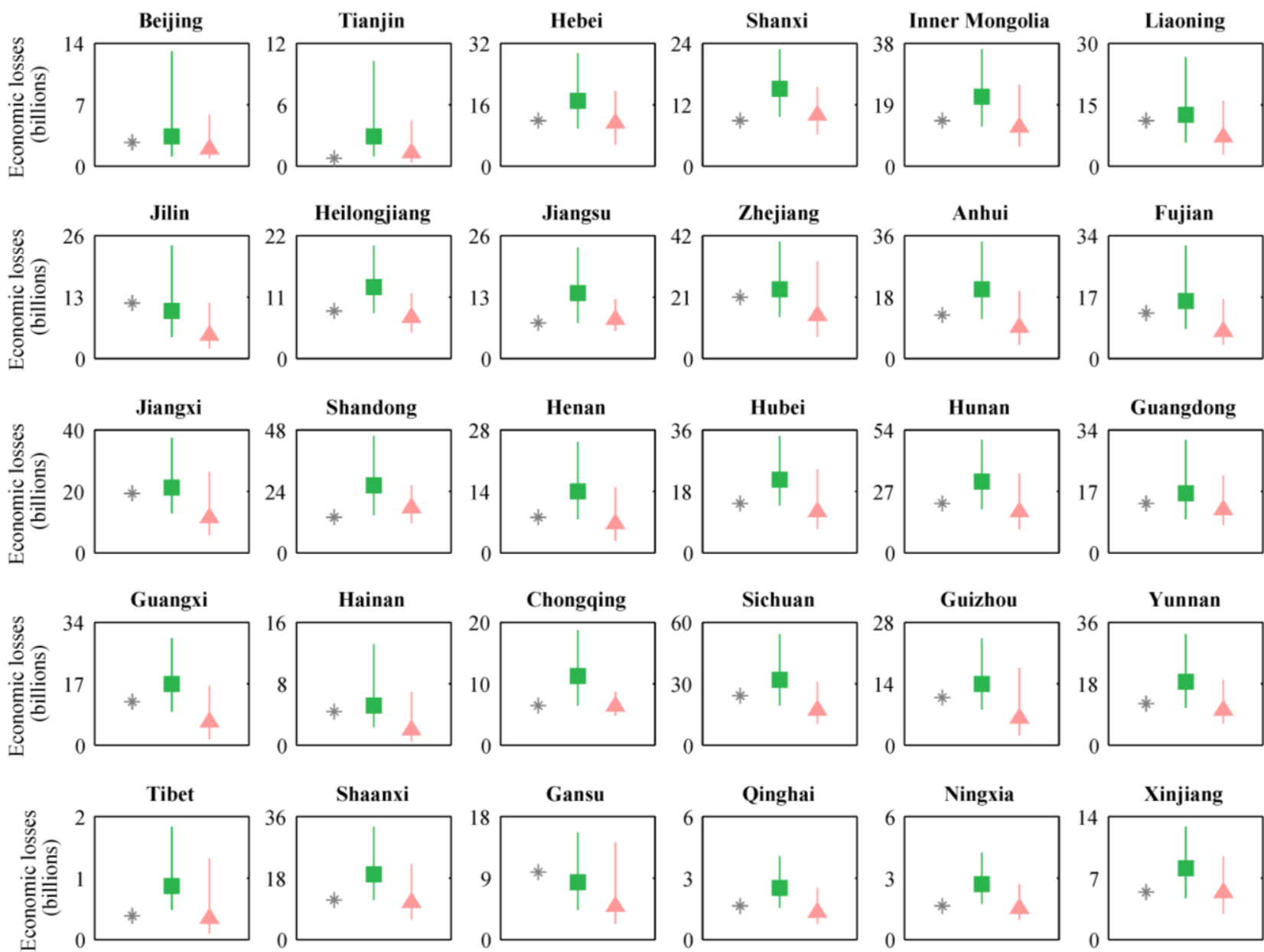

Figure 3 Average economic losses recorded in 2000-2012 and predicted in 2015-2050 under RCP2.6 (2.5-97.5\% uncertainty bound with median value)

\subsection{National socioeconomic risk}

The national socioeconomic damages in different conditions from 2015 to 2050 are presented in Figure 4. First, we investigate how future economic and demographic scenarios affect national damages by comparing the estimates with and without development. The predictions without development (i.e. GDP and population are fixed as those in 2012) are made by Model 1. It can be seen that both affected people and economic losses increase with the effect of climate change alone. Under the development scenario, the total number of people affected decreases slightly to 383.17 million by 2050 due to a reduction of the national population. Yet, the percentage of affected people in the total population grows with a small change over the entire period. As a result of growing GDP the economic losses are expected to have an upward trend in the long term, and climate change and development 
induce losses over 500 billion CNY by 2050. Second, the damages with development are estimated by Model 1 and Model 2 to show how adaptation works. The number of people affected is projected to have a continuous reduction, while the economic losses are stable over the period. Overall, these comparisons indicate that there would be a high risk of damages with growing exposure to extreme events that could be mitigated under economic development. The estimated damages by Model 1 are important for risk planning which needs to consider potential more severe consequences. Furthermore, Model 2 reveals the possible benefits from enhanced adaptive capacity due to economic development.
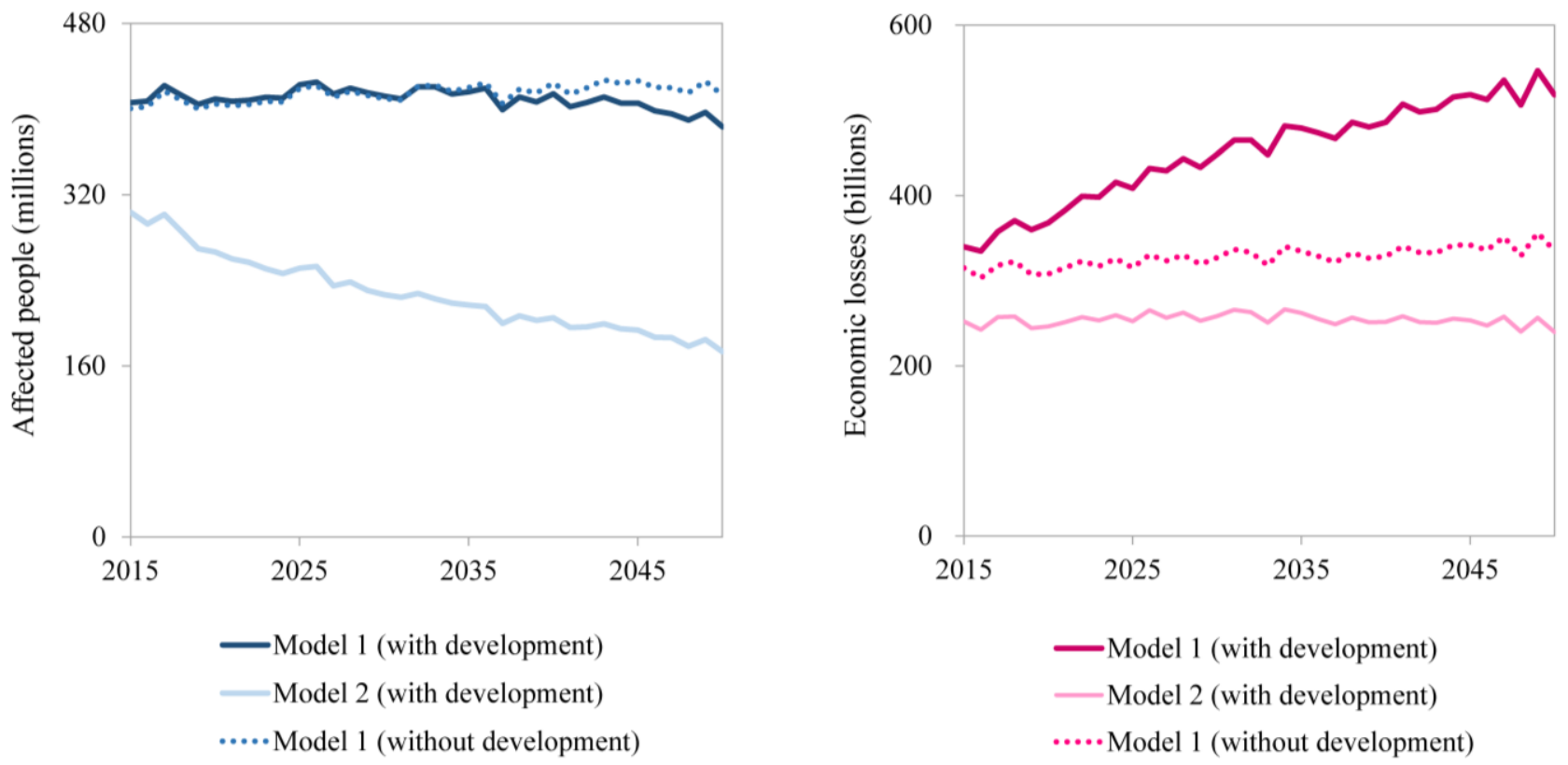

Figure 4 National socioeconomic damages (median values) during 2015-2050 under RCP2.6

\subsection{The impacts of climate change on socioeconomic damages}

In this section we compare the estimated socioeconomic damages in the past (1971-1999) and future (2015-2050) climate conditions to reveal the effect of climate change alone, with the economic and demographic scenarios for the two periods fixed to the values in 2012. The changes in extreme events under RCPs are presented in Figure S7-S10, and we use Model 1 to estimate the damages in the two periods. As shown in Figure S11, the number of people affected for all provinces in the future would become bigger. The mean relative change in the median value is $15.2 \%$ (15.7\% and 14.4\%) under RCP2.6 (RCP4.5 and RCP6.0). Similarly, we find that future climate condition raises the economic losses of provinces (Figure S12) with an average change in the median value of 
annual medians during two periods are displayed in Figure 5. There are some differences in the estimates between climate models, however, they all eventually indicate that both affected people and economic losses would be more serious in the changing climate condition. We also notice that the ranges of annual medians of damages under RCP4.5 are generally wider, which implies that the impacts of extreme events vary greatly during future period. Yet, the regional temperature and precipitation lead to fewer flood-related and heat events in some regions under RCP6.0, and thus there is no higher damage for the whole country.
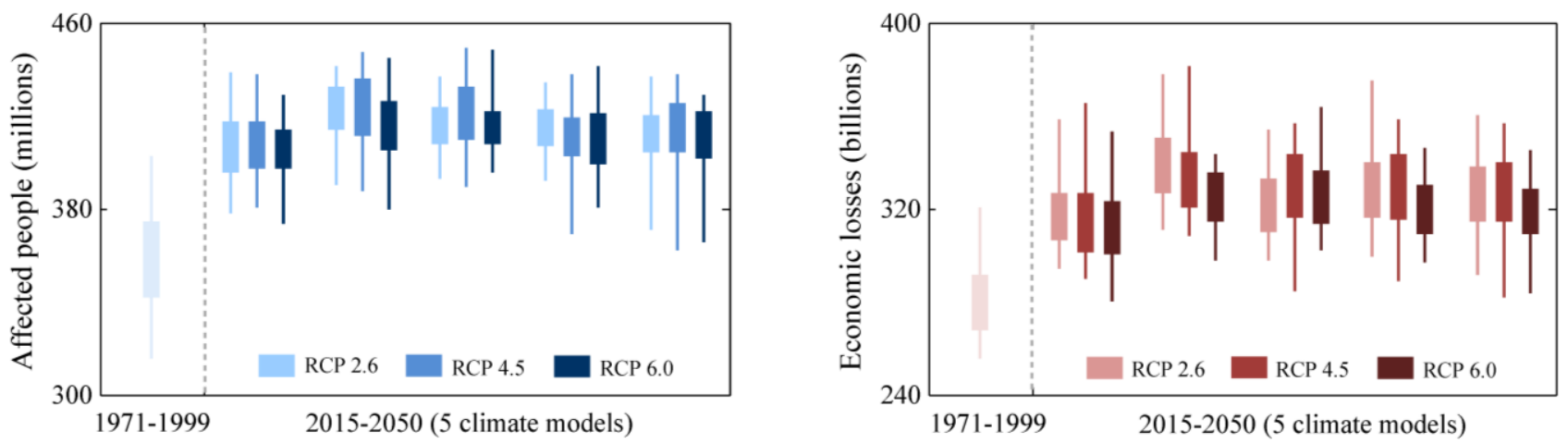

Figure 5 Annual medians of national socioeconomic damages in the periods of 1971-1999 and 2015-2050 with the same development situations in 2012. Each box shows the $25^{\text {th }}$ and $75^{\text {th }}$ percentile and whiskers extend to the $2.5^{\text {th }}$ and $97.5^{\text {th }}$ percentile. The damages during $2015-2050$ are predicted by 5 climate models respectively.

\section{SUMMARY}

This paper investigated China's socioeconomic risk from extreme events under climate change over the next few decades with a focus on sub-national heterogeneity, and quantification of uncertainty. The main points of the analysis are summarized below.

(1) A hierarchical Bayesian model provides a useful way to quantify the uncertainties in model parameters, structural relation and predictions. It keeps a region's characteristics, and also allows appropriate grouping of the information in different regions. The posterior distributions of socioeconomic damages are of importance for planning risk adaptation and mitigation. We show that the approach reduces uncertainties of estimates, and thus provides a better quantification on the uncertainty of damage costs. 
(2) Southwest provinces (Guizhou, Chongqing, Yunnan, Guangxi, and Sichuan), central provinces (Jiangxi, Hubei and Hunan), and Hainan Island are likely to have a larger percentage of population at risk with exposure effect only. As for economic losses, most of the southwest and central areas are generally higher, especially for Sichuan and Hunan. Some high-income provinces would also be faced with heavy losses.

(3) GDP per capita which reflects adaptive capacity can significantly decrease the number of people affected by extreme events. The average affected people with adaptation effect in 2015-2050 are expected to be lower than the average of historical observations. Yet, the economic losses with adaptation effect are projected to be close to the historical averages due to growing economic exposure to extremes.

(4) The impacts of climate change are significant, and the socioeconomic damages of all provinces in the future would shift to a higher level on average. Overall the national damages separately estimated from climate models have upward trends in the changing climate condition.

There are several limitations of our analysis. First, the number of extreme events rather than recorded weatherrelated disasters is used to explore the impacts on damages. We believe that the chosen extremes are relevant to the corresponding disasters, and can serve as reasonable proxies. The estimated relationships facilitate the projection of socioeconomic damages, since it is easier to obtain future extreme events. Second, the relationship for damage estimation is composed of simple terms. Apart from the variables (e.g. the frequency of extremes and the scales of population and economy) included in this paper, some other determinants (e.g. the magnitude of extreme event) could also affect socioeconomic damages. Thus, a more comprehensive consideration of determinants could be explored in the future. Further developments could be focused on model improvement to better include various climate factors. Moreover, nonlinearity for some of the predictors is not considered in our study. For example, the relationship between damages and economic development might be nonlinear, which is still under discussion. Third, future scenarios are questionable. The real development of climate and socioeconomic conditions might deviate from the assumptions made today. The uncertainty in economic and demographic development is not involved here, but note the Bayesian framework could actually integrate all the uncertainties and provide a more informative estimate of socioeconomic damages. Further studies can also explore the impacts with the different combinations of climate and socioeconomic scenarios. 
The possible ranges of socioeconomic damages estimated by two models eventually offer some insights for adaptation and mitigation plans in China. First, the economic risk of high-income areas is high due to a large exposure to extreme events. For better risk management, reasonable and effective plans are needed, especially for emergency measures for catastrophe. Second, economic development is essential for vulnerable areas. In China, the less developed provinces may experience heavier relative damages, because of low adaptive capacity and high frequency of severe disaster. Economic development in these areas may help build basic capacity for response to climate change. Third, climate change may cause more damages from extreme events, and this should be combined in the integrated assessment model to further compare appropriate climate polices.

\section{ACKNOWLEDGMENTS}

The authors are grateful for the financial support from the National Natural Science Foundation of China (NSFC) (Nos. 71521002 and 71020107026) and the China Scholarship Council. For their roles in producing, coordinating, and making available the ISI-MIP model output, we acknowledge the modeling groups (HadGEM2-ES, IPSLCM5A-LR, MIROC-ESM-CHEM, GFDL-ESM2M, and NorESM1-M) and the ISI-MIP coordination team. We thank all colleagues from Center for Energy \& Environmental Policy Research, Beijing Institute of Technology for providing helpful suggestions. We also appreciate the anonymous reviewers and the editor for their insightful and constructive comments that substantially improved the manuscript.

\section{REFERENCES}

Arnell NW, Lloyd-Hughes B (2014) The global-scale impacts of climate change on water resources and flooding under new climate and socio-economic scenarios. Climatic Change 122: 127-140.

Bahinipati CS, Venkatachalam L (2016) Role of climate risks and socio-economic factors in influencing the impact of climatic extremes: a normalisation study in the context of Odisha, India. Regional Environmental Change 16: 177-188.

Barr R, Fankhauser S, Hamilton K (2010) Adaptation investments: a resource allocation framework. Mitigation and Adaptation Strategies for Global Change 15: 843-858.

Cavallo E, Powell A, Becerra O (2010) Estimating the direct economic damages of the earthquake in Haiti. The Economic Journal 120: F298-F312.

Chen X, Hao Z, Devineni N, Lall U (2014) Climate information based streamflow and rainfall forecasts for Huai River basin using hierarchical Bayesian modeling. Hydrology and Earth System Sciences 18: 1539-1548. 
Devineni N, Lall U, Pederson N, Cook E (2013) A tree-ring-based reconstruction of Delaware river basin streamflow using hierarchical Bayesian regression. Journal of Climate 26: 4357-4374.

Fankhauser S, McDermott TKJ (2014) Understanding the adaptation deficit: Why are poor countries more vulnerable to climate events than rich countries? Global Environmental Change 27: 9-18.

Gelman A, Hill J (2007) Data Analysis Using Regression and Multilevel/Hierarchical Models. Cambridge University Press, New York.

Gelman A, Rubin DB (1992) Inference from iterative simulation using multiple sequences. Statistical science 7: 457 472.

Hallegatte S, Green C, Nicholls RJ, Corfee-Morlot J (2013) Future flood losses in major coastal cities. Nature Climate Change 3: 802-806.

Hawkins E, Osborne TM, Ho CK, Challinor AJ (2013) Calibration and bias correction of climate projections for crop modelling: An idealised case study over Europe. Agricultural and Forest Meteorology 170: 19-31.

Hsiang SM (2010) Temperatures and cyclones strongly associated with economic production in the Caribbean and Central America. Proc Natl Acad Sci U S A 107: 15367-15372.

IPCC (2012) Managing the risks of extreme events and disasters to advance climate change adaptation. Cambridge University Press, Cambridge and New York.

IPCC (2013) Climate Change 2013: The Phyisical Science Basis. Cambridge University Press, Cambridge and New York.

IPCC (2014) Climate Change 2014: Impacts, Adaptation, and Vulnerability. Part A: Global and Sectoral Aspects. Cambridge University Press, Cambridge and New York.

Kahn ME (2005) The death toll from natural disasters: The role of income, geography, and institutions. Review of Economics and Statistics 87: 271-284.

Kebede AS, Nicholls RJ (2012) Exposure and vulnerability to climate extremes: population and asset exposure to coastal flooding in Dar es Salaam, Tanzania. Regional Environmental Change 12: 81-94.

Kellenberg DK, Mobarak AM (2008) Does rising income increase or decrease damage risk from natural disasters? Journal of Urban Economics 63: 788-802.

Kwon HH, Lall U, Engel V (2011) Predicting foraging wading bird populations in Everglades National Park from seasonal hydrologic statistics under different management scenarios. Water Resources Research 47.

Lazzaroni S, van Bergeijk PAG (2014) Natural disasters' impact, factors of resilience and development: A meta-analysis of the macroeconomic literature. Ecological Economics 107: 333-346.

Liu J, Hertel TW, Diffenbaugh NS, Delgado MS, Ashfaq M (2015) Future property damage from flooding: sensitivities to economy and climate change. Climatic Change 132: 741-749.

Lloyd SJ, Kovats RS, Chalabi Z, Brown S, Nicholls RJ (2016) Modelling the influences of climate change-associated sea-level rise and socioeconomic development on future storm surge mortality. Climatic Change 134: 441-455.

Mendelsohn R, Emanuel K, Chonabayashi S, Bakkensen L (2012) The impact of climate change on global tropical cyclone damage. Nature Climate Change 2: 205-209.

Morss RE, Wilhelmi OV, Meehl GA, Dilling L (2011) Improving Societal Outcomes of Extreme Weather in a Changing Climate: An Integrated Perspective. Annual Review of Environment and Resources 36: 1-25.

Nordhaus WD (2010) The economics of hurricanes and implications of global warming. Climate Change Economics 1: $1-20$. 
Noy I (2009) The macroeconomic consequences of disasters. Journal of Development Economics 88: 221-231.

O'Neill BC, Kriegler E, Riahi K, Ebi KL, Hallegatte S, Carter TR, et al. (2014) A new scenario framework for climate change research: the concept of shared socioeconomic pathways. Climatic Change 122: 387-400.

Patt AG, Tadross M, Nussbaumer P, Asante K, Metzger M, Rafael J, et al. (2010) Estimating least-developed countries' vulnerability to climate-related extreme events over the next 50 years. Proc Natl Acad Sci U S A 107: 13331337.

Pielke RA (2007) Future economic damage from tropical cyclones: sensitivities to societal and climate changes. Philosophical Transactions of the Royal Society a-Mathematical Physical and Engineering Sciences 365: 2717-2729.

Preston BL (2013) Local path dependence of US socioeconomic exposure to climate extremes and the vulnerability commitment. Global Environmental Change 23: 719-732.

Raschky PA (2008) Institutions and the losses from natural disasters. Natural Hazards and Earth System Sciences 8: 627-634.

Rogelj J, McCollum DL, Reisinger A, Meinshausen M, Riahi K (2013) Probabilistic cost estimates for climate change mitigation. Nature 493: 79-83.

Schumacher I, Strobl E (2011) Economic development and losses due to natural disasters: The role of hazard exposure. Ecological Economics 72: 97-105.

Seo SN (2014) Estimating tropical cyclone damages under climate change in the Southern Hemisphere using reported damages. Environmental \& Resource Economics 58: 473-490.

Smit B, Wandel J (2006) Adaptation, adaptive capacity and vulnerability. Global Environmental Change 16: 282-292.

Stan Development Team (2015) Stan Modeling Language: Users' Guide and Reference Manual, Stan Version 2.6.0.

State Flood Control and Drought Relief Headquarters of China (2013) Bulletin of Flood and Drought Disaster in China 2012. China Water \& Power Press, Beijing.

Sun X, Lall U, Merz B, Dung NV (2015) Hierarchical Bayesian clustering for nonstationary flood frequency analysis: Application to trends of annual maximum flow in Germany. Water Resources Research 51: 6586-6601.

Thomas V, Albert JRG, Hepburn C (2014) Contributors to the frequency of intense climate disasters in Asia-Pacific countries. Climatic Change 126: 381-398.

Tol RSJ (2002) Estimates of the damage costs of climate change - Part II. Dynamic estimates. Environmental \& Resource Economics 21: 135-160.

Toya H, Skidmore M (2007) Economic development and the impacts of natural disasters. Economics Letters 94: 20-25.

van den Bergh J, Botzen WJW (2014) A lower bound to the social cost of CO2 emissions. Nature Climate Change 4: 253-258.

van Vuuren DP, Carter TR (2014) Climate and socio-economic scenarios for climate change research and assessment: reconciling the new with the old. Climatic Change 122: 415-429.

Wang CH, Khoo YB, Wang XM (2015) Adaptation benefits and costs of raising coastal buildings under storm-tide inundation in South East Queensland, Australia. Climatic Change 132: 545-558.

Wei YM, Mi ZF, Huang Z (2015) Climate policy modeling: An online SCI-E and SSCI based literature review. Omega 57: 70-84. 
Zhou Y, Li N, Wu WX, Liu HL, Wang L, Liu GX, et al. (2014) Socioeconomic development and the impact of natural disasters: some empirical evidences from China. Natural Hazards 74: 541-554.

416 